\title{
$62-70$ 洞庭湖湖滩矮埂保水生态灭螺水域
}

\section{育珠性能的试验研究}

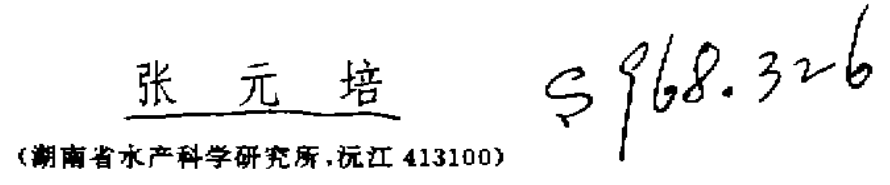

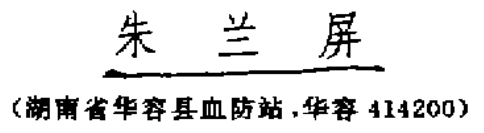

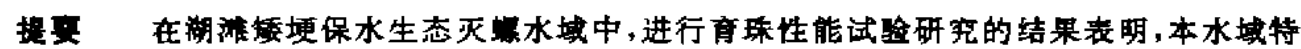

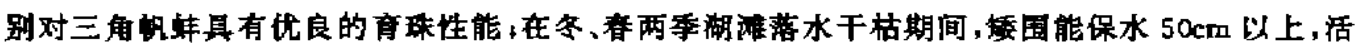
和等卵港死率达 $100 \%$ 。

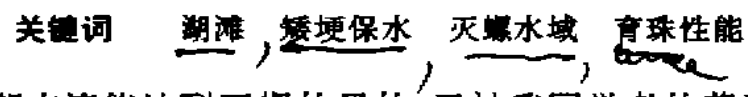

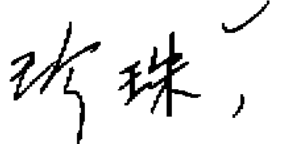

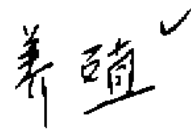

长期水海能达到灭夥的目的,已被我国学者的若干试验所证实 ${ }^{[0]}$ 。但在湖滩血吸虫病易 感地带,建筑的矮埂保水水域中,进行生态灭望并结合育珠生产，在国内、外尚未见有报道。

洞庭湖每年春、夏两季常有多饮洪峰港没湖滩，最高水位达 8-9m。为了探索本水域生

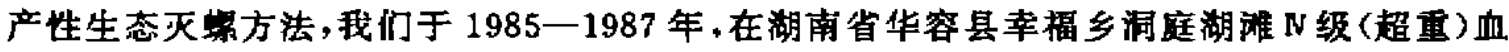
吸虫病易感地带 ${ }^{[2]}$, 进行了矮埂保水育珠和灭塄的研究试验。

本矮围水面积 $15 \times 10^{4} \mathrm{~m}^{2}$,其中 $700 \mathrm{~m}^{2}$ 水面进行育珠试验,两年来珍珠产值达 7000 元，

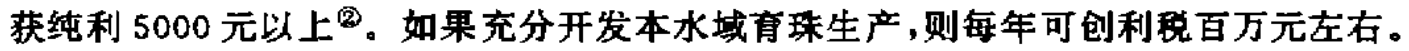

本水域的灭㩧试验表明，矮围的洞庭湖滩近堤低洼地带，连续水海 11一22 个月后,在有

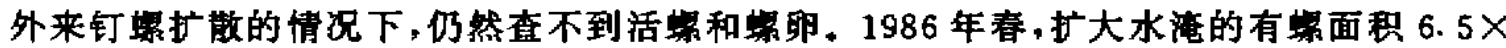
$10^{4} \mathrm{~m}^{2}$, 经连续水港 $2-3$ 个月, 近期钉是校正死亡率为 $72.11 \%(88.46-58.62 / 100-$ $58.62)$, 蛙卵密度威少 $84.57 \%(37.45-5.78 / 37.45)$,收到了当年大大降低聚口密度的效

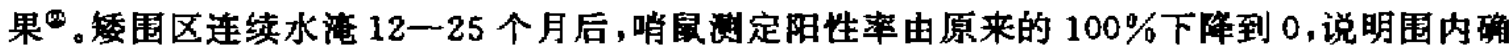
无活㩧存在. 本试验研究收到了生态灭蛙和育珠生产双重性的效应。现将试验情况报告如 下。

\section{一、材料与方法}

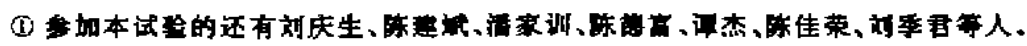

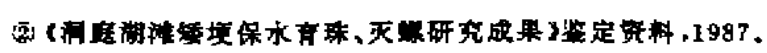

本文于 1991 年 12 月 18 日收到, 1992 年 5 月6 日改回。 


\section{（一）矮围生态灭蠌水域情况}

湖南省华容县幸福乡大堤外的洞庭湖洲难, 湖草丛生, 钉螺 (Oncomelania hupensis Gredler 和 Katayama nosophora Robson) ${ }^{[s]}$ 密布, 它们是日本血吸虫 (Schistosoma japonicum Katsurada) 的中间宿主 ${ }^{[4.6 .9 .10]}$ 。由于是距堤内居民点 $200 \mathrm{~m}$ 以内, 属 $\mathrm{N}$ 级超重血 吸虫病易感地带。选择这一地带的东沠村堤外 $1000 \mathrm{~m}$ 宽度地段作为试输区,四周就地取土 建筑围。埂面高程 $30.0 \mathrm{~m}$ (吴松海面 0 点计,下同), 宽 $2 \mathrm{~m}$, 埂内、外坡比为 $1: 2$, 楼围面积 $15 \times 10^{4} \mathrm{~m}^{2}$ 。

每年 5 月上旬左右, 洞庭湖水位逐渐上张, 开始海没矮围, 围内最高洪峰水位达 8--9m; 10 月中旬左右的末次洪峰过后, 㮃围开始保水, 水位高程保持在 $28.3 \mathrm{~m}$ (水深 $0.5 \mathrm{~m}$ 以上), 能达到保水灭螺和保蚌越冬要求。

\section{(二)试验蚌}

养殖经插核手术的三角帆蛙 (Hyriopsis cumingii Lea) ${ }^{[3-5]} 505$ 只和仅经植片手术的裙 纹冠蚌 (Cristaria plicala leach) ${ }^{[3-5]} 304$ 只。全部挂养在矮围水域中的固定式篗架上。簙架 面积 $20 \mathrm{~m} \times 35 \mathrm{~m}=700 \mathrm{~m}^{2}$ 。

\section{（三)对照水域}

1. 内湖型育珠水域 取湖南省汉寿县特种水产研究所的内湖型鱼珠混莽水域。面积 $10 \mathrm{hm}^{2}$, 常年平均水深 $1.83 \mathrm{~m}$, 采取柂肥和投草等半精前式经营措施, 鱼产量 $3000 \mathrm{~kg} / \mathrm{hm}^{2}$ 左 古，珍珠常年产量和质量性状水平一般。

2. 哑河型育珠水域 取汉寿县沦港珍珠场的哑河型育珠水域。本喛河长度 $15 \mathrm{~km}$, 常年 水深平均 3.1m。自 1964 年断流成哑河后, 即开始经营渔业生产, 1984 年开始鱼珠混养。由 于有沦港镇居民和沿河两岸村民 3800 人的生活污水和农田㞎水不断注人,养鱼、育珠生产 性能良好。

3. 池塘型育珠水域 取华容县塔市水产养殖场的一只池塘型育珠水域。池面积 $0.6 \mathrm{hm}^{2}$, 水深 $1.8 \mathrm{~m}$, 属精养水面,年鱼产量 $4000 \mathrm{~kg}$ 左右。

在各对比水域中, 吊养与试验水域相应数量的二种育珠蚌。作业蛙的手术蚌和细胞小片 蚌规格一致,插核手术蚌的插核规格和插㧡数量亦一致。无核珍珠和有核珍珠的手术作业, 分别由同一植珠手完成 中。

\section{(四)测试方法}

试验水域和各对照水域水质理化性状指数的润定,采用常规水化学分析法; 浮游生物量

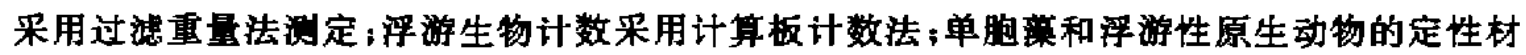
料经绍丁氏液(Schaudinn's Fluid)固定后鉴定分析。

对各水域的参试育珠蚌的手术成活率、养殖成活率、固核率和成珠率等及时进行检 河[3.8]。珍珠采收后,对各水域的参试蚌所产珍珠，分别作出质量性状分析(8)。

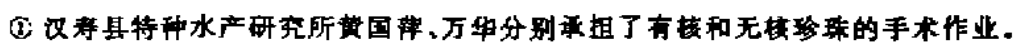

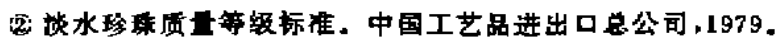

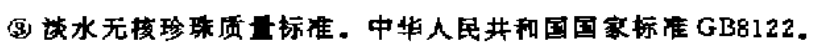




\section{二、试验结果和分析}

\section{（一）水域的理化性状}

\section{1. 蝼围水域水位的周年变化}

从 1986 和 1987 年婑围水域水位周年变化曲线(图 1)中可看出, 从 11 月到翌年 4 月的 半年低水位期间，婑围水域具典型的池塘型育珠水域的特性; 5-10 月的半年高水位期间, 则具内湖或哑河型育珠水域的特性。

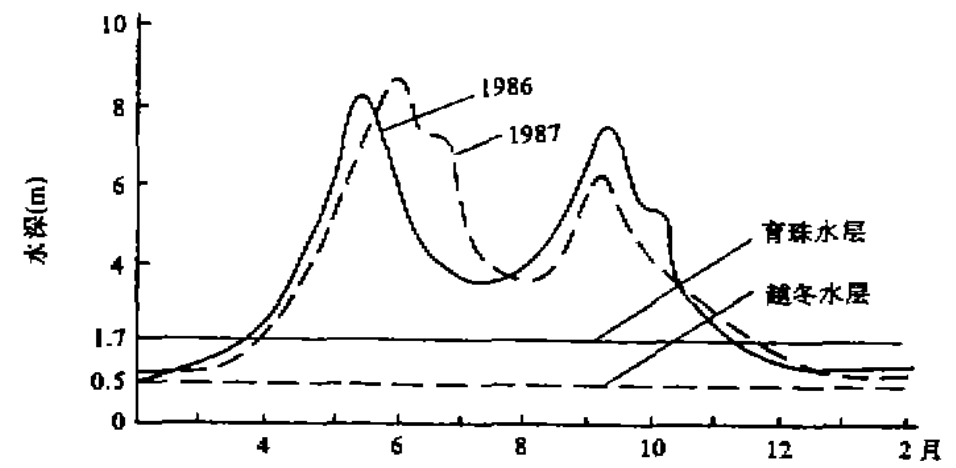

图 1 槙水域水位周年变化(1986-1987 年)

Fig. 1 Annual change of the water level in the low-dike waters (1986-1987).

\section{2. 来殖水层珍珠质沉积最佳水遈的期限}

智围水域在全年中,最佳珍珠质沉积水温累计达 142 天(1986 和 1987 年的平均值), 比 池塘型对比水域多 72 天; 比内湖型和哑河型对比水域多 47 天(表 1 )。

从图 2 绘制的各水域育珠水层温度曲线可以看出,1986 和 1987 年的 7.8 月高温季节, 除婑围试验水域有珠水层的水温仍然处于珍珠质沉积最佳水温范图外，池塘型、内湖型和哑 河型各对比水域的育珠水层的水温，均跃出了珍珠质沉积最佳水温范圈.尤其是对比的池塘 型水域,在 7 月中旬到 8 月下旬期间，育珠水层的温度往往达到或超出三角蝴育珠蛙的 “热昏迷”界限。因此,必须定期补充或更换新水。

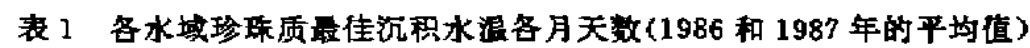

Tab. 1 Day number of the most suitabe water temperature for the pearl deposition each month in various waters. (mean value of 1986-1987)

\begin{tabular}{|c|c|c|c|c|c|c|c|c|}
\hline 水 城 & 5月 & 6月 & 7月 & 8月 & 9月 & 10 月 & 11 月 & 合计 \\
\hline 攺圈水域 & 14 & 30 & 31 & 30 & 20 & 17 & 0 & 142 \\
\hline 池境水城 & 17 & 21 & 0 & 0 & 20 & 12 & 0 & 70 \\
\hline $\begin{array}{l}\text { 内湖水城 } \\
\text { 国河水地 }\end{array}$ & 14 & 30 & 0 & 7 & 30 & 14 & 0 & 95 \\
\hline
\end{tabular}

注、各水㳦高水层水盟到定的时间为每日下午 3 时左右。 


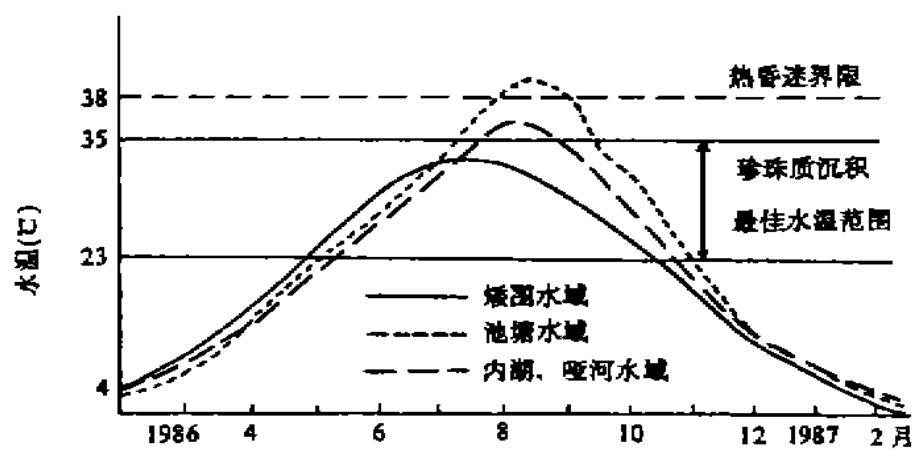

图 2 国水域育珠水层水温周年变化曲线及其珍珠最佳沉积水温期限与对比水城的比较

Fig. 2 Annual change curve for temperature in the pearl culture water layer of the low surround waters, comparson of the best water temperature range of pearl deposition in the low-dike waters

\section{3. 水化学性状}

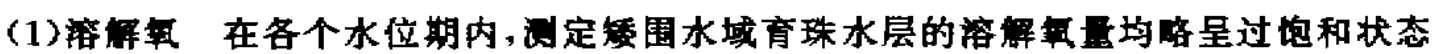

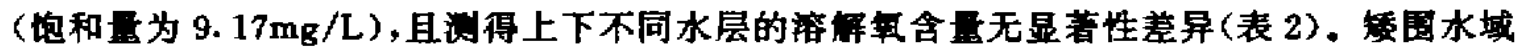
水位的形成与其须䇣的波动, 是由于动态洪峰的张落所构成。因此, 即使是在春夏之交期间, 亦不致出现池塘型等闭锁性水域水体上下循环停濡的现象。因而,开放性的短圈水域,从表 到底的各水层的氧含量能基本上挡近一致。这一点,正是婑围水域中的育珠蝆能在洪蜂期, 顺利渡过“潜埋式”养殖方式的重要生态条件.

\section{表 2 各水位期内挂吊蚌生活天数及水体古武至}

Tab. 2 At various water levels living day number of the hanging freshwater mussel and oxygen content of the waters

\begin{tabular}{|c|c|c|c|c|c|c|}
\hline 水位稆 & $0-1$ & $1-2$ & $2-3$ & $3-4$ & $4-5$ & $5-8$ \\
\hline 挂员蚲生活天数 & 271 & 251 & 36 & 57 & 17 & 8 \\
\hline 击事 $(\mathrm{mg} / \mathrm{L})$ & 9.54 & 9.59 & 9.74 & - & 9.36 & 9. 53 \\
\hline
\end{tabular}

从秋季洪水下退起,直至翌年 4 月,计有半年的时间,婑围水域虽然呈现出典型池塘型 育珠水域的特点，但水体中溶望量依然处于饱和状态，比对比池塘水域育珠水层的溶翚量高 出 $5.170 \mathrm{mg} / \mathrm{L}$ (水温 $20 \pm 1.0^{\circ} \mathrm{C}$ 时)（表 3 )。

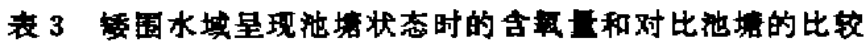

Tab. 3 Comparison of the oxygen content of the low-dike waters and controlled pong.

\begin{tabular}{|c|c|c|c|}
\hline \multirow{2}{*}{ 水嵹类思 } & \multicolumn{3}{|c|}{ 素 (mg/L) } \\
\hline & 音 但 & 值 & 平均 \\
\hline 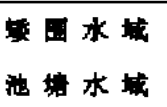 & $\begin{array}{l}9.59 \\
5.04\end{array}$ & $\begin{array}{l}9.50 \\
3.71\end{array}$ & $\begin{array}{r}9.545 \\
4.375\end{array}$ \\
\hline
\end{tabular}


（2）其他水化学指标 水温 $20 \pm 1.5 \mathrm{C}$ 时。水体游离 $\mathrm{CO}_{2}$ 含量为 $0.87 \pm 0.0 \mathrm{Bmg} / \mathrm{L}$, 铮 离子 $\left(\mathrm{Ca}^{2+}\right)$ 浓度为 $44.9 \pm 0.06 \mathrm{mg} / \mathrm{L}, \mathrm{pH}$ 值为 $6.9 \pm 0.13, \mathrm{H}_{2} \mathrm{~S}$ 和 $\mathrm{CH}_{4}$ 含量为 0 值。这些与 珍珠生长有着直接关系的水化学指标, 和各对比水域相比。皿示了矮围水域优良的育珠性能 (表 4)。

表 4 圈水域的其他水化性状与各对比水域的比较

Tab. 4 Comparison of the water quality parameters of the low-dike waters and controlled waters

\begin{tabular}{|c|c|c|c|c|c|c|c|c|}
\hline 水 & 塂 & 类 & 型 & $\begin{array}{c}\text { 檕 } \mathrm{CO}_{2} \\
(\mathrm{mg} / \mathrm{L})\end{array}$ & $\begin{array}{c}\mathrm{Cg} z+ \\
(\mathrm{mg} / \mathrm{L})\end{array}$ & $\mathrm{pH}$ & $\begin{array}{c}\mathrm{H}_{\mathrm{s}} \mathrm{S} \\
(\mathrm{mg} / \mathrm{L})\end{array}$ & $\begin{array}{c}\mathrm{CH}_{+} \\
(\mathrm{mg} / \mathrm{L})\end{array}$ \\
\hline 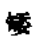 & 国 & 水 & 棫 & $0.87 \pm 0.08$ & 44. $9 \pm 0.06$ & $6.9 \pm 0.13$ & 0 & 0 \\
\hline 沈 & 塂 & 水 & 棫 & $0.93 \pm 0.06$ & $19.3 \pm 1.4$ & $6.8 \pm 0.26$ & 0.51 & 0.78 \\
\hline 内 & 湖 & 水 & 塂 & $0.84 \pm 0.05$ & $20.8 \pm 1.1$ & $6.9 \pm 0.14$ & 0.28 & 0.36 \\
\hline 吗 & 河 & 水 & 域 & $0.88 \pm 0.05$ & 34. $3 \pm 1.7$ & $7.0 \pm 0.11$ & 0.40 & - \\
\hline
\end{tabular}

育珠水域水层的化学性状和底土的化学性状呈明显的动态平街反应 ${ }^{[3]}$ 。因此、水底泥积 物的化学性质也和水层的化学性质一样,均能直接影响到水域的育珠性能。1986 年 5 月, 对 各水域泥积物所作多项化学性状测定的结果列于表 5. 从表中的数据，可分析出不同水城掉 落于底泥中的育珠蛙死亡率高低不同的原因。1986 年冬,各水域落底育珠蚝的死亡率是: 池 塘水域为 $80 \%$,内湖和哑河水域为 $67 \%$,婑围水域为 0 . 池塘水域泥积物中的落底蚌死亡率

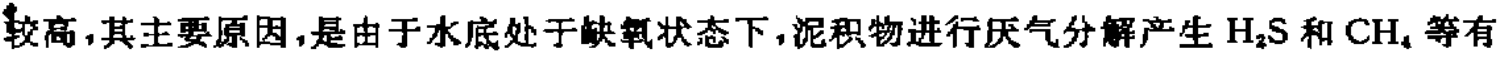
毒气体所致。内湖和哑河型育珠水域，由于人类多年来的生产经营活动,造成水质迅速富营 养化,使底层水的含秤量减少, 以及从流入水中带来的多种有害污染物质,在水域底部沉积 物中逐渐积聚而达到甚至超过致死育珠蚌的浓度，因而落底育珠蚌的死亡率亦较高。矮围水 域底土含砂量为 $37.54 \%$, 化学耗氧量(COD) 低, 且泥积物中硅薯土含量高达 $13.31 \%$, 因此 适合三角帆蚌埋栖。

表 5 围水城底土化学性状与各对比水域的比交

Tab.5 Comparison of chemical state of bottom soil in the low-dike waters and controlled waters

\begin{tabular}{|c|c|c|c|c|c|c|c|c|c|}
\hline \multicolumn{4}{|c|}{ 水城类型 } & $\mathrm{pH}$ & 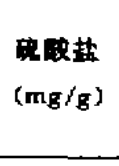 & $\begin{array}{l}\text { 全酸化吻 } \\
\text { ( } \mathrm{mg} / \mathrm{g})\end{array}$ & $\begin{array}{c}\mathrm{H}_{2} \mathrm{~S} \\
(\mp \pm) \\
(\mathrm{mg} / \mathrm{B})\end{array}$ & $\begin{array}{c}\mathrm{CH} \\
(\mathrm{mg} / \mathrm{g})\end{array}$ & $\begin{array}{c}\text { COD } \\
(\mathrm{mg} / \mathrm{g})\end{array}$ \\
\hline 笨 & 国 & 水 & 城 & 7.00 & 0.0171 & 0.0240 & 0. 0000 & 0.0013 & 9. 39 \\
\hline 池 & 堵 & 水 & 域 & 5.60 & 0.5625 & 0.0260 & 0.0064 & 0.0208 & 42.55 \\
\hline 内 & 胡 & 水 & 域 & 6.21 & 1.0870 & 0.0391 & 0.0023 & 0.0145 & 28.23 \\
\hline 理 & 河 & 水 & 城 & 6. 29 & 0.4924 & 0.0287 & 0.0041 & 0.0117 & 19.68 \\
\hline
\end{tabular}

\section{（二)水城的生物学性状}

1. 定性测定 1986 年 3 月- 1987 年 2 月, 对矮国育珠水域的饵料生物 (包括有机碎肩) 
进行了测定，其各月的平均值如图 3 所 示。从图中看出饵料浮游生物量在一年 之中, 出现 4-5 月和 9-11 月两吹高 峰, 均是以硅藻类 (Bacillariophyta)、金 染类 (Chrysophyta) 为主的两次䇣殖盛 期。这些荡类是三角帆蚌的适口饵料 ${ }^{[5]}$, 其生物量足够 $700 \mathrm{~m}^{2}$ 水面养殖 1000 只 育珠蚌索饵的需要。

即使是在夏季, 矮围水域也难以形 成蓝藻类 (Cyanophyta) 和绿藻类 (Chlorophyta)的优势种群。因此, 蓝㩰类 中某些能引起育珠蛙发生莯毒素中毒的 种类, 例如水华鱼腥藻 (Anabaena flos-

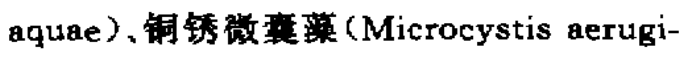
nosa) 和德红页 (Oscillatoria

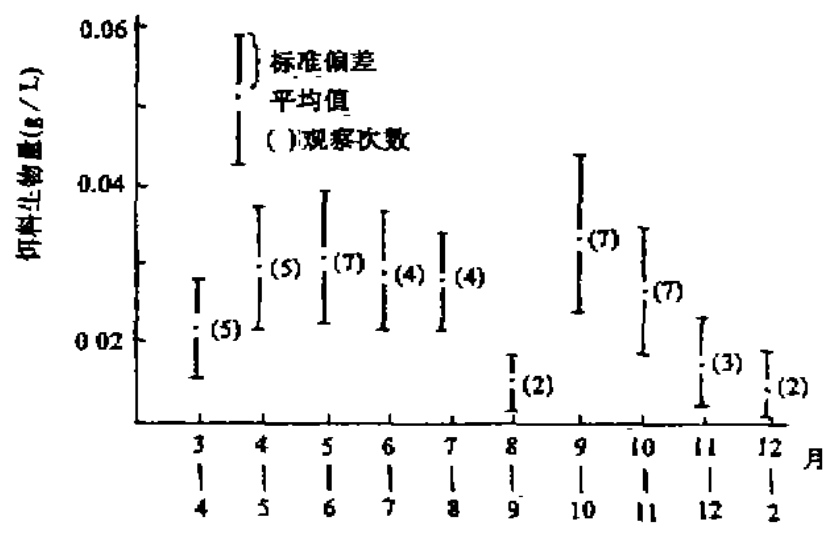

国 3 蜪料游生物至的周年变动(1986 年 3 月-1987 年 2 月

Fig. 3 Anoual change of the plankton food biomass (3. 1986-2.1987) rubescens) 等 ${ }^{[3]}$, 数量很少。在 19851987 年的一个完整的育珠周期中, 没有发生澡毒素中毒的死蚌现象。

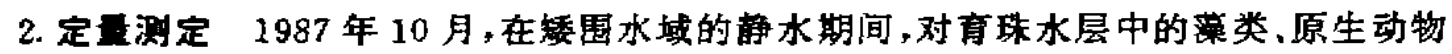
和轮虫分别测定计数, 其结果列于表 6。从表中看出, 矮围水城中对三角帆蚌适口性种类的

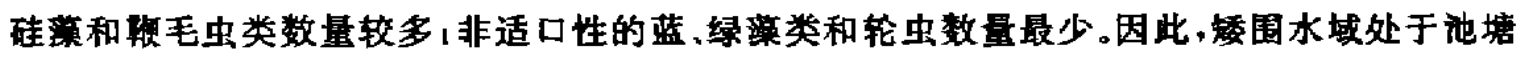
型结构育珠期间,佴料生物性択优于普通池塘育珠水城。

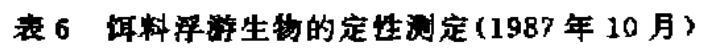

Tab.6 Qualitative measurement of the food plankton(10,1987)

\begin{tabular}{|c|c|c|c|c|c|c|c|c|c|c|c|}
\hline \multirow{2}{*}{ 水 } & \multirow{2}{*}{ - } & \multirow{2}{*}{ 类 } & \multirow{2}{*}{ 죠 } & \multicolumn{5}{|c|}{ 車类(万个/L) } & \multicolumn{2}{|c|}{ 国生动物 $(\uparrow / L)$} & \multirow{2}{*}{ 轮虫 $(\uparrow / L)$} \\
\hline & & & & 砂党 & 蒀、缘䡛 & 金素 & ation & 表靠 & 轩毛虫 & 軎毛虫 & \\
\hline 模 & EI & 水 & + & 12047 & 5104 & 6979 & 4107 & 1793 & 1426 & 5013 & 869 \\
\hline 散 & 塂 & 水 & 2 & 14160 & 21017 & 8083 & 5433 & 2105 & 1733 & 3103 & 1013 \\
\hline 内 & 愺 & 水 & 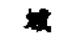 & $1053 !$ & 10041 & 6451 & 3916 & 1944 & 1546 & 2169 & 874 \\
\hline E & 河 & 水 & xat & 11017 & 9655 & 5966 & 4142 & 1740 & 1344 & 1786 & 843 \\
\hline
\end{tabular}

（三)珍珠质量性状分析

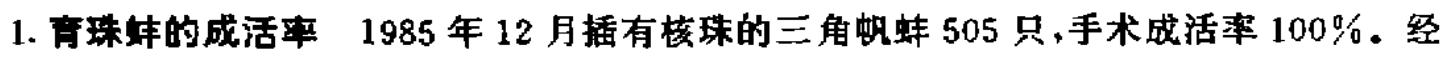
观察, 1986 年养直死亡 26 只,成活率 $94.9 \%: 1987$ 年死亡 17 只,成活事 $96.7 \%$, 从表 7 所 示各水城育珠蚌的成活率数据看出, 楼围水城明显具有育珠蚌最佳存活性能。 
表 7 婑国水域三角帆蛼成活率与对比水域的比较

Tab. 7 Comparison of survival rate of cultured pearl mussel in the low-dike waters and controlled waters

\begin{tabular}{|c|c|c|c|c|c|c|}
\hline \multirow{2}{*}{ 水 } & \multirow{2}{*}{+} & \multirow{2}{*}{ 类 } & \multirow{2}{*}{ 开 } & \multirow{2}{*}{$\frac{\text { 手术成佸臬(\%) }}{1985 \text { 年 }}$} & \multicolumn{2}{|c|}{ 非城活事(\%) } \\
\hline & & & & & 1986 年 & 1987 年 \\
\hline 5 & 国 & 水 & + & 100 & 94.9 & 96.7 \\
\hline 被 & 素 & 水 & 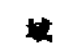 & 81 & 68.3 & 54.6 \\
\hline 内 & 计 & 水 & t & 87 & 81. 7 & 77.4 \\
\hline F & 河 & 水 & $\Rightarrow$ & 90 & 83.5 & 77.8 \\
\hline
\end{tabular}

2. 玲珠的质 1985 年 12 月插植有核珍珠的三角帆蚌,于 1987 年 11 月采收珍珠时, 共计成活 462 只(采收时不慎掉落湖底 80 只), 从 382 只怀珠蛙中采收到有核珍珠 $1200 \mathrm{~g}$ (3$20 \mathrm{Momme}$ )。平均每蚌产珠 7.63 页，计 $3.18 \mathrm{~g}(0.85 \mathrm{Momme}) ;$ 最大珠 $8.0 \mathrm{~mm}$ ，最小 $6.3 \mathrm{~mm}$, 平均珠径 $6.71 \mathrm{~mm}$ 。皮层 (珍珠层) 厚度为 $0.87 \pm 0.04 \mathrm{~mm}$ 。珍珠色相比率为: 白色系 统占 $21 \%$,枌红色系统占 $9 \%$ ，金色系统占 $40 \%$ ，银色系统占 $18 \%$,杂色珠占 $12 \%$ 。珍珠的商 品形态是:正园珍珠 (Round pearls)占 $43.0 \%$, 就蚪珠 (Tadpole shaped pearls)占 $15 \%$, 滴 水形珍珠 (Drop shaped pearls)占 $10 \%$,卵形珍珠 (Egg pearls)占 $15 \%$, 双联珠 (Twinned pearls) 占 $5 \%$, 附壳珍 (Attached shell pearls) 占 $10 \%$, 无商品价值的废次珍珠 (Poor pearls)占 $2 \%$ 。

1985 年 12 月，用橧绞冠蛘作无核珍的手术蛙 304 只,1987 年 9 月采收到 160 只,保 存率 $52.63 \%$,采收无核珍珠 $400 \mathrm{~g}$ (合 $106.7 \mathrm{Momme}$ ), 平均每蚌产珠 $2.5 \mathrm{~g}$ 。

根据珍珠的厘码大小、商品形态、色彩和光泽，以及皮层㚖度与皮质细感度等质量性状

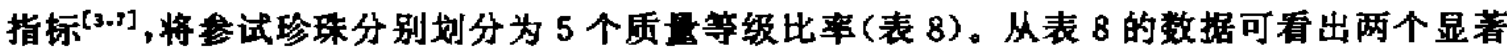

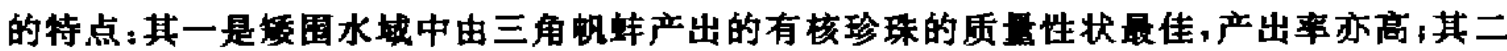

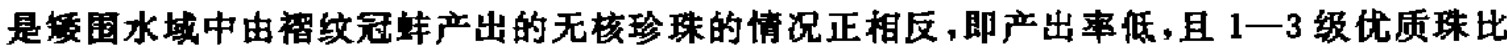
率,只有其他类型水域的 $50 \%$ 左右。

表 8 各水坡飨珠质吾性状分析

Tab. 8 Analysis of the pearl quality in various waters

\begin{tabular}{|c|c|c|c|c|c|c|c|c|c|}
\hline \multirow{3}{*}{ 水 } & \multirow{3}{*}{\multicolumn{2}{|c|}{+3}} & \multirow{3}{*}{ 型 } & \multicolumn{3}{|c|}{ 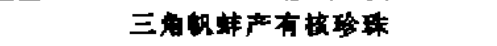 } & \multicolumn{3}{|c|}{ 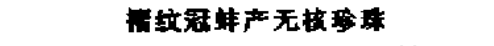 } \\
\hline & & & & \multicolumn{3}{|c|}{ 慗姆比事 $(\%)$} & \multicolumn{3}{|c|}{ 事比来(\%) } \\
\hline & & & & 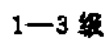 & 4 蜗 & 5 数 & $1-3$ & 4 & 5 织 \\
\hline 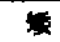 & B. & 水 & t & 41. 3 & 45.2 & 13. 5 & 8.6 & 53.4 & 38.0 \\
\hline w & 墙 & 水 & 中 & 17.9 & 53.6 & 28.5 & 18. 5 & 44. 3 & 37.2 \\
\hline 内 & 消 & 水 & + & 27.8 & 58.1 & 14. 1 & 14.8 & 42.2 & 43.0 \\
\hline 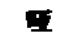 & 河 & 水 & 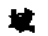 & 25.4 & 50.4 & 24.2 & 11.8 & 40.6 & 47.6 \\
\hline
\end{tabular}

在每年高温季节 ( $7-8$ 月)的高水位期间,楼围水域中固定式篗架上的育珠蚌,是在“潜

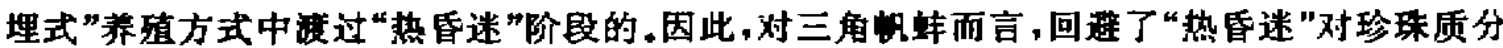




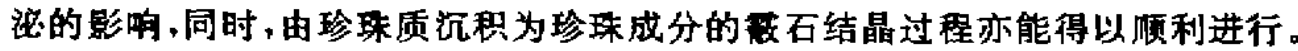

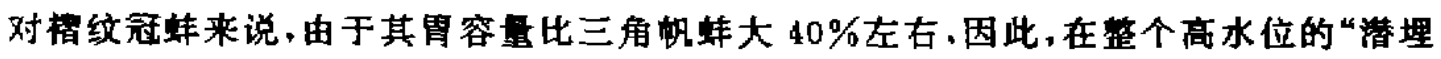

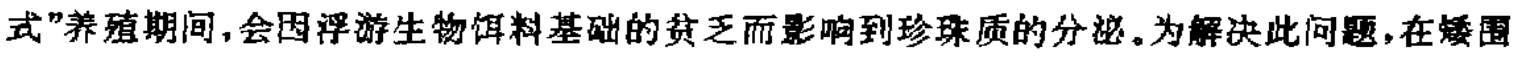

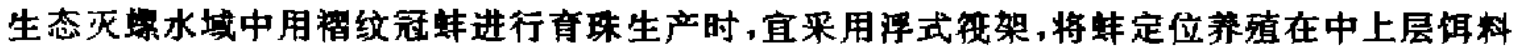
生物量较大的水层中.

$$
\text { 三、小 结 }
$$

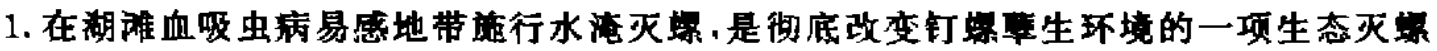
方法,可以在一定范围内消除易感地带的感染性。

由于本灭瑟方法不使用任何化学药物,有利于保持鱼、贝、莱等水产算源不受破坏和 保护生态环境不受污染。

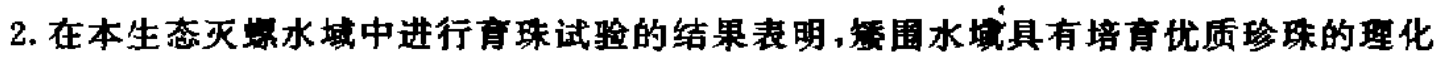
和生物学性状，尤其适合三角帆蚌育珠生产的生态要求。

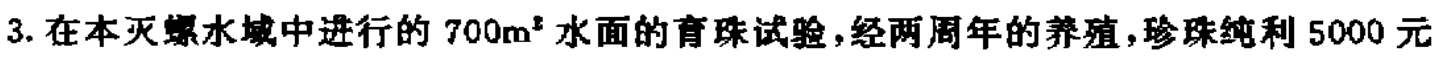
以上,如约全部水面开发育珠生产，年创利税可达百余万元。此种高放益的生产与生态灭琛

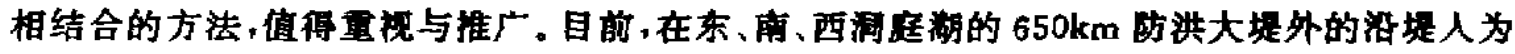

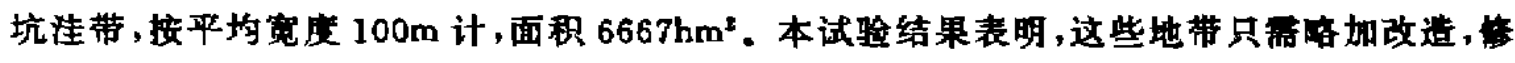
建短围保水,便能进行育珠生产和生态灭蜬。

\section{类文}

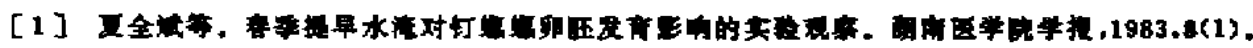

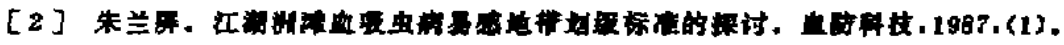

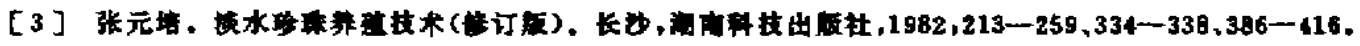

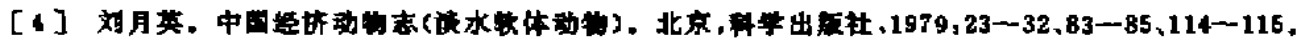

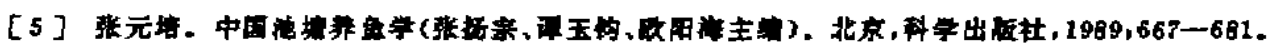

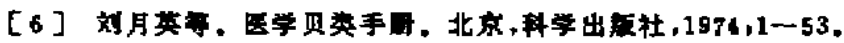

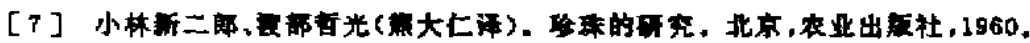

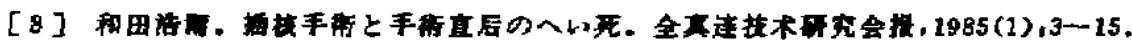

[9] Bartsch,P. A new intermediate host of the Asiatic blood fluke Schistosoma ja poaricum Kateurata, j. wash. Acad, sci. $1939,29(4)$.

[10] Davis ,G. m. ,A systematic study of Oncomelania hupengis chivi (Gsstropode, Hydrobiidec), mslocologia , 1968 , 7 (1). 


\title{
EXPERIMENTAL RESEARCH ON THE PERFORMANCE OF PEARL CULTURE IN THE LOW DIKE RETAINING WATERS FOR ECOLOGIC ELIMINATING SNAIL (ONCOMELANIA) OF THE LAKE BEACH OF DONGTIN LAKE
}

\author{
Zhang Yuanpei \\ (Hunar Institule of Fisheries, Yarjuang 413100 ) \\ Zhu Nanbing \\ (Station of the Snail Fever contrat in Huarong caunty , Huran province, Huarong 113200 )
}

\begin{abstract}
An experiment of the pearl culture was made in the low dike retaining waters and ecologic eliminating snail (Oncomelania) of the lake beach of Dongtin Lake. The result shows that the waters are of favourable conditions for the pearl culture.

During the dropping in water level and the drying of the lake beach in winter and spring, the low dike can maintain a depth of above $50 \mathrm{~cm}$ of water. Mortalities of living snail (Oncomelania) and snail egg may reach up to $100 \%$.

Under natural conditions, the plankton in the water body of the pearl culture amounts to 30000 indivduals $/ \mathrm{L}$; dissolved oxygen $9.54-9.74 \mathrm{mg} / \mathrm{L}, \mathrm{Ca}^{3+}$. concentration $44.9 \pm$ $0.06 \mathrm{mg} / \mathrm{L} ; \mathrm{PH}$ value $6.9 \pm 0.13, \mathrm{H}_{2} \mathrm{~S}$ and $\mathrm{CH}_{4} 0$ value in the water body of the pearl culture when water temperature is at $20 \mathrm{C}$. These states of the water chemistry and biology are suitable for the requirement of the mussel ( $H_{y}$ riopsis cumingii) growth. Production rate of the pearl of excellent quality may reach to $41.3 \%$, being $13.5 \%, 15.9 \%$ and $23.4 \%$ higher than that of the inland lake $(27.8 \%)$, mute river $(25.4 \%)$ and pond $(17.9 \%)$ respectively.
\end{abstract}

Key words Lake beach, low dike retaining water, waters of eliminating snail, performance of the pearl culture 